\title{
ESCRITA, PERFORMANCE E REPRESENTAÇÃO DE SI
}

\section{Nayara Marfim Gilaberte Bezerra* \\ Pontifícia Universidade Católica do Rio de Janeiro}

Resumo: Partindo da hipótese de que o advento das novas tecnologias e a grande proliferação das escritas de si em blogs e redes sociais são sintomas de época que dialogam com o campo dos estudos literários e apontam para um novo objeto de pesquisa, o presente trabalho tem como objetivo traçar um breve panorama de um fenômeno cultural de nosso tempo, relacionado ao conceito de autoria como performance. A partir do entendimento de que o escritor contemporâneo representa diferentes papeis para se fazer percebido, falando de si e inscrevendo suas experiências em diferentes cenários, trabalharemos com os espaços de e(u)nunciação utilizados por João Paulo Cuenca, escritor que, nos últimos anos, fez das plataformas digitais importantes meios para divulgação, apresentação e criação de suas obras. Sobre o autor, nos interessou, mais, pesquisar a relação existente entre as estratégias por ele adotadas e o lugar de destaque que Cuenca ocupa no disputado circuito artístico-literário da atualidade.

Palavras-chave: Escritas de si. Performance. Autoria. João Paulo Cuenca.

\section{Introdução}

A curiosidade que deu origem ao presente trabalho nasceu de uma antiga proposta de analisar a produção diarística contemporânea, por meio de uma investigação acerca da proliferação das escritas de si como tendência cultural da atualidade, e de suas relações com o uso das novas tecnologias digitais, eletrônicas e interativas. Ao debruçarmo-nos em vastos conteúdos disponíveis na web, deparamo-nos, entretanto, com uma grande quantidade de blogs e perfis em redes sociais de escritores contemporâneos, que utilizam a internet como meio para o compartilhamento de seus relatos pessoais. Estávamos, pois, diante de um amplo material a ser trabalho que conduzia nossa investigação para uma curiosa questão: o que leva, na atualidade, escritores com livros publicados a se aventurarem em diferentes possibilidades narrativas e autobiográficas na rede mundial de computadores?

Buscando responder esta pergunta, investigamos, inicialmente, o percurso histórico

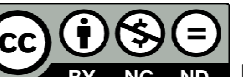

BY NC ND Esta obra está licenciada sob uma Licença Creative Commons.

\footnotetext{
* Mestranda em Literatura, Cultura e Contemporaneidade pela Pontifícia Universidade Católica do Rio de Janeiro. Especialista em Literatura Brasileira pela Universidade do Estado do Rio de Janeiro. Bacharel em Psicologia pela Universidade Federal do Rio de Janeiro.
} 
que nos conduz, na atualidade, a desconfiar da assinatura autoral como conceito natural no campo das artes. Partindo da hipótese de que a autoria pode ser entendida como uma performance midiático-literária, analisamos alguns espaços digitais de enunciação, aqui compreendidos como novos cenários da escrita. Apoiados na ideia de que os meios interferem diretamente nos conteúdos que neles (e a partir deles) são construídos, nos dedicamos, por fim, ao estudo de duas obras do escritor brasileiro João Paulo Cuenca, e de suas experimentações de ampliação do espaço literário. Sobre o autor, nos interessou, mais, pesquisar a relação existente entre as estratégias por ele adotadas e o lugar de destaque que Cuenca ocupa no disputado circuito artístico-literário da atualidade.

Da curiosidade que levou à redação do presente trabalho, resta uma infinidade de possíveis questões. Dentre as possibilidades ainda não desenvolvidas, está uma análise comparativa do cenário literário brasileiro em perspectiva com outras culturas e a possibilidade de investigar, junto ao público leitor, qual a motivação que os leva a consumir obras e vidas que se criam, ininterruptamente, em livros e telas. Das considerações que conseguimos tecer, deixamos, aos que se interessem pelo tema, o convite para prosseguir na leitura.

\section{A autoria como performance literária}

Testemunhamos, na atualidade, uma grande proliferação das escritas em primeira pessoa. Embora este cenário não destoe de outros fenômenos da sociedade contemporânea, que com o avanço da cultura midiática do final do século $\mathrm{XX}$ tem produzido cada vez mais uma crescente espetacularização da intimidade, aponta para uma mudança de paradigma no que se refere à noção de autor.

Culturalmente construída, a noção de autor passou por diferentes momentos ao longo da história. Se atualmente vivemos um momento em que a figura daquele que escreve se tornou ícone midiático fundamental, trazendo à tona diferentes questões relacionadas ao processo de construção das obras literárias, esse fenômeno não se apresentou sempre assim. Para melhor apresentar o lugar do qual pretendemos escrever o presente trabalho, iniciaremos nosso texto com um recuo histórico que buscará desconstruir a idéia da assinatura autoral como conceito natural no campo das artes.

Inicialmente, é importante destacar que nem sempre os discursos foram assinados por autores. Desde a Antiguidade até o início da Idade Média, as histórias viviam um processo contínuo de criação, uma vez que aqueles que as contavam tinham o direito de decidir quais conteúdos incluir, retirar ou modificar durante o próprio ato narrativo. Naquela 
época, as histórias circulavam sem que houvesse uma preocupação com seu fechamento e eram valorizadas sem que se colocasse em questão a autoria, já que o valor e a autenticidade estavam mais relacionados ao fato de serem narrativas antigas e tradicionais, do que pela assinatura de um autor que autenticasse a obra. É a partir da Renascença que diferentes fatores contribuem para a invenção e a exaltação do indivíduo, trazendo a figura do autor para o campo literário. Soma-se a isso, segundo Foucault (2006, p. 47), o fato de os textos terem passado a ser assinados por autores na medida em que os discursos assumiram a possibilidade de serem encarados como transgressores e passíveis de punição, entrando, consequentemente, no regime de propriedade característico de nossa sociedade, que estabelece regras sobre direitos de autor, reprodução e etc. Em suas palavras,

\footnotetext{
Os textos, os livros, os discursos começaram efetivamente a ter autores (outros que não personagens míticas ou figuras sacralizadas e sacralizantes) na medida em que o autor se tornou passível de ser punido, isto é, na medida em que os discursos se tornaram transgressores. Na nossa cultura (e, sem dúvida, em muitas outras), o discurso não era, na sua origem, um produto, uma coisa, um bem; era essencialmente um acto - um acto colocado no campo bipolar do sagrado e do profano, do lícito e do ilícito, do religioso e do blasfemo. Historicamente, foi um gesto carregado de riscos antes de ser um bem preso num circuito de propriedades. (FOUCAULT, 2006, p. 47)
}

Nos anos sessenta do século XX, há, entretanto, uma forte mudança nesse cenário, que evidencia uma crítica do sujeito e a consequente descentralização da figura autoral. Embora Maurice Blanchot já anunciasse pela primeira vez em 1955 a decadência do autor ao, no primeiro capítulo de seu livro $O$ espaço literário (1987), anunciar a independência do texto em relação a quem o escreve, é na década de 60, e no auge do estruturalismo, que dois textos tornam-se símbolo desse movimento: “A morte do autor”, de Roland Barthes (1988) e "O que é um autor?", de Michael Foucault (2006). Negando a existência de um autor que precedesse sua obra, ambos os teóricos destacam, cada um a seu modo, a ideia de que o autor, ao mergulhar na obra, aceita o seu desaparecimento (morte) uma vez que só a obra, através da linguagem, fala.

Em Barthes (1988), parte-se da ideia de que a escrita é a destruição de toda voz, o lugar onde toda identidade se perde. Isso porque o autor nasce junto com a obra e escrever é, portanto, um ato performativo, cujo conteúdo não vai além do próprio ato pelo qual é enunciado. Segundo Barthes em “A morte do autor”, não há, no texto, um significado último a ser decifrado, uma vez que a escrita é um puro ato de inscrição, comparada a uma superfície rasa, na qual o que se espera do leitor (ponto de encontro de todas as citações e referências de que a narrativa é feita) é que ele siga sua estrutura. Leiamos: 
(...) o escritor moderno nasce ao mesmo tempo que seu texto; não é, de forma alguma, dotado de um ser que precedesse ou excedesse a sua escritura, não é em nada o sujeito de que o seu livro fosse predicado; outro tempo não há senão o da enunciação, e todo texto é escrito eternamente aqui e agora. (BARTHES, 1988, p. 68)

Foucault, na famosa e já citada conferência que recebeu o título de "O que é um autor?" (2006), disserta sobre essa questão a partir da relação do texto com o seu produtor. Foucault salienta, metaforicamente, que o tema da escrita destinada a conjurar a morte (ao conferir a imortalidade ao herói ou adiar a morte através da incessante narrativa) havia sofrido alterações, passando então a estar ligada ao sacrifício da própria vida do escritor, que, ao mergulhar na escrita, abre mão de toda a sua história. Dessa forma, entende-se a escrita como um ato de afastamento do autor, que anula todos os seus caracteres individuais e deixa, no texto, apenas a marca de sua ausência. Nesse sentido, Foucault conclui que o autor, sujeito empírico, ao entrar na escrita, dá lugar à função autor, que vem caracterizar o modo de circulação e funcionamento dos discursos na sociedade.

Atualmente, trabalha-se com a ideia de um retorno do autor. Seguiremos, agora, a provocação de Ana Cláudia Viegas, que tenciona a tendência estruturalista de negar a importância daquele que escreve, ao afirmar:

(...) a figura do autor nunca deixou de rondar a noção de obra. Pelo menos no campo literário, permanece em nós, leitores, a vontade de encontrar do outro lado da página um ser que nos abrace; o que mantém o fetiche em torno de exposições de objetos pertencentes aos escritores (livros, máquina de escrever, fotos, documentos pessoais, entre outros) ou da oportunidade de ter a presença do autor, seja em programas de televisão ou ao vivo, nas tão badaladas "mesas de escritores" (VIEGAS, 2007, p. $15)$.

Buscaremos, nesse sentido, dialogar com pesquisadores contemporâneos que trazem para a cena literária do século XXI diferentes pontos de vista relacionados ao fenômeno da proliferação dos discursos em primeira pessoa e da apresentação performativa de autores da atualidade como ícones midiáticos fundamentais.

Philippe Lejeune, importante teórico dos estudos autobiográficos, disserta, em “A imagem do autor na mídia”, sobre o novo espaço ocupado pelos autores contemporâneos na grande mídia. Segundo Lejeune, em uma retrospectiva histórica, inicialmente eram os textos literários os responsáveis pelo fomento do desejo, nos leitores, de conhecer aquele que escreve. Nessa época, para ocupar o vazio deixado pela ausência do escritor, os leitores recorriam às formas biográficas canônicas (autobiografias, diários etc.) para buscar as informações que desejavam para se sentirem mais próximos daqueles que, através dos textos escritos, proporcionavam-lhes o prazer da leitura. Lejeune aponta que, a partir do fim do 
século XIX, formas não canônicas de aproximação entre leitores e autores, potencializadas com o avanço da cultura midiática do século XX, entram para esse cenário de interação. A crescente participação midiática do escritor, por sua vez, parece subverter a lógica fetichista da curiosidade autoral: se outrora eram os livros lidos que despertavam no leitor o interesse pelo autor, podemos arriscar dizer que, muitas vezes, na atualidade, é a performance do autor enquanto ícone midiático que desperta, no leitor, o interesse pela sua produção textual.

A esse novo cenário, soma-se a constatação de que, cada vez mais, o autor, além de assumir os papéis de escritor e promotor daquilo que escreve, participa, na pós-modernidade, da trama dos textos escritos, jogando, com o texto, a sua presença enquanto personagem e matéria de ficção. Essa tendência literária, que brinca com a noção de sujeito empírico e é denominada por diferentes autores de autoficção, traz consigo a questão da autoria como elemento fundamental da tessitura da narrativa. Faz-se, entretanto, necessário destacar que esse autor que retorna para o espaço literário contemporâneo não é o autor cuja morte fora enunciada por Foucault e Barthes. Trata-se, pois, de um autor que participa da ficção enquanto escritor, promotor e personagem sem, todavia, deter a autoridade pela verdade do texto. Assim expõe Diane Klinger (2007), em seu livro Escritas de si, escritas do outro:

O conceito de autoficção vem de Doubrovsky, que o elaborou a partir da concepção psicanalítica da subjetividade como produção, ou seja, a ficção que o sujeito cria para si mesmo: "a autoficção é a ficção que eu, como escritor, decidi apresentar de mim mesmo e por mim mesmo, incorporando, no sentido estrito do termo, a experiência de análise, não somente no tema, mas também na produção do texto". Essa reinvenção do jogo entre o sujeito empírico e o ficcional, marcante na literatura do presente, tem direcionado a reformulação dos estudos de textos em $1^{\mathrm{a}}$ pessoa. (DOUBROVSKY apud KLINGER, 2007 p. 52).

Em seu livro, Diane Klinger apresenta a "a hipótese de que o "retorno do autor" - a auto-referência da primeira pessoa - talvez seja uma forma de questionamento do recalque modernista do sujeito" (KLINGER, 2007, p. 36). A hipótese defendida por Klinger, com a qual trabalharemos, é de que "o autor retorna não como garantia última da verdade empírica e sim apenas como provocação, na forma de um jogo que brinca com a noção de sujeito real" (KLINGER, 2007, p. 47). Devido à sua relevância para este trabalho, cabe ainda citar outras observações:

Que sentido dar ao retorno na cena literária de uma escrita do eu? Essa primeira pessoa é uma máscara produzida pelo teatro irônico da cultura midiática ou ela implica uma outra visão da obra? O termo retorno também não é evidente: quando datar esse retorno, e se há retorno é um retorno do mesmo? Qual é o sujeito que retorna? Evidentemente não se trata da figura sacrossanta do autor, tal como ela é sustentada pelo projeto autobiográfico tradicional. [Aqui] o lugar da ficção entranha 
uma dessemantização do eu, que perde sua coerência biográfica e psicológica (KLINGER, 2007, p. 38).

Portanto, falar do retorno do autor enquanto subjetividade que volta ao cenário da escrita implica questionar, necessariamente, a noção empírica de sujeito real. O sujeito cuja performance pretendemos estudar é plural, se constitui nas narrativas que enuncia e se dispersa nos meios que utiliza como plataforma para a sua voz. Faz-se com isso necessário problematizar também a noção de verdade discursiva: para além dos conceitos de verdadeiro e falso, optamos por seguir com a ideia de que aquele se que enuncia é um sujeito fragmentado, disperso nos vários discursos midiáticos de que faz parte.

Nesse sentido, pensar na enunciação daquele que escreve, é pensar na pluralidade dos meios de circulação dos discursos. Uma vez que, conforme falamos, o autor contemporâneo atua como ícone midiático, torna-se também importante analisar os espaços de enunciação, uma vez que esse autor de hoje se inscreve, para além de em seus conteúdos textuais, em blogs, redes sociais virtuais, entrevistas televisionadas, congressos, festas e feiras literárias, dentre outras incontáveis possibilidades. Para abarcar essa questão, trabalharemos, a seguir, com a noção de "espaço biográfico", desenvolvida por Leonor Arfuch, escritora e professora argentina, especialista em análise de discurso e crítica cultural.

Para formular sua hipótese, Leonor Arfuch dialoga com Philippe Lejeune e com a noção de pacto autobiográfico, apresentada pelo autor em seu livro de mesmo nome. Em $O$ pacto autobiográfico (2008), Lejeune discute as noções de autobiografia, ressaltando que, para que um texto seja lido como tal, é necessário atentar para o pacto de leitura entre o leitor e o texto estabelecido pelo autor; pacto este que se afirma a partir da identificação entre autornarrador-personagem. Segundo o teórico, esse contrato de identificação é firmado pela utilização no nome próprio, que assina o texto e atesta a existência de um sujeito autor fora da obra - sujeito esse que se apresenta como real e responsável pela verdade autobiográfica do texto.

Leonor Arfuch (2010), por sua vez, se apoia no conceito desenvolvido por Lejeune para criar o mais ampliado "espaço biográfico". Nele, a autora caracteriza a articulação entre diversos gêneros discursivos contemporâneos ligados aos relatos de experiências pessoais e à exposição pública da intimidade. Segundo a autora, o espaço biográfico vai além do gênero narrativo canônico, estendendo-se a novas modalidades de registro como as entrevistas, redes sociais virtuais e blogs, que, juntos constituem o corpus de análise para a leitura de uma vida na contemporaneidade. 
É dentro desta perspectiva, de entendimento do espaço biográfico como um lugar de experimentação ativa e construção dinâmica do eu que se enuncia, que levantamos, para reflexão, algumas questões: É ainda possível trabalharmos com a noção de uma realidade discursiva, associada a uma narrativa comprometida com a verdade do sujeito? Podemos ignorar o fato de que a diversidade dessa perspectiva oferece, para os escritores hoje em atividade, uma nova matéria a ser trabalhada? Nesse contexto, quais são os limites que nós devemos dar aos estudos literários contemporâneos? De que forma devemos apreender esse jogo pluridimensional viabilizado pela constante inserção do autor na mídia? O que dele devemos esquecer?

Giorgio Agamben, em $O$ autor como gesto (2007), nos oferece algumas dicas para desdobrar as referidas questões. Apoiado na já citada conferência "O que é um autor", o teórico utiliza a máxima de Beckett citada por Foucault ("Que importa quem fala, alguém disse, que importa quem fala") para nos mostrar que já havia, ali expressa, a contradição da existência do autor. Isso porque sempre há, ainda que não importe, alguém que fala e não está, portanto, morto. Para Agamben, o autor, ao mergulhar na escrita, veste o papel de morto e se atesta unicamente pelos vestígios da sua ausência. Sua teoria apresenta, então, o paradigma da presença-ausência do autor na obra como um gesto e oferece um novo estatuto à função do autor, que é jogar com a obra. A relação presença-ausência do autor na obra é entendida, portanto, como um jogo no qual cabem, por exemplo, falsas pistas, desvios e pequenas mentiras. Por isso, o autor permanece sempre não realizado e não dito, uma vez que, nesse jogo, a obra não explica a vida de seu criador e abre um espaço, o lugar que ficou vazio, para que a leitura se torne possível.

Temos aí mais uma chave que busca abrir o mistério da exploração midiática após a denominada morte do autor. Seria, pois, o cenário contemporâneo, de curiosidade e valorização da vida real, que nos apresenta a chave para aquilo que ousamos chamar de retorno do autor. Estaria também na curiosidade do leitor, que busca preencher as lacunas pelas quais os autores se tornam presentes na obra, um combustível possível para a atual exploração midiática daquele que escreve. Estaria, também, na pluralidade dos meios que hoje compõe o espaço biográfico, a possibilidade de lermos vidas que se tecem ao mesmo tempo em que se jogam, interativamente, em livros, blogs, entrevistas e redes sociais.

Uma vez situados na perspectiva histórica que nos embasa, buscaremos analisar a possibilidade de compreender o jogo que se tece em torno da cena literária contemporânea a partir das transformações que o surgimento de espaços de livre enunciação, proporcionados 
pelo advento da internet, abre para a constante representação de si. Utilizaremos, para tanto, o já mencionado conceito de espaço biográfico apresentado pela autora argentina Leonor Arfuch. Dele nos interessa principalmente a ideia de interatividade, proposta pela teórica a partir do entendimento deste como um espaço de articulação entre múltiplos gêneros e formas diversas pelas quais as vidas se narram ao mesmo tempo em que se criam.

Para a teórica argentina, a multiplicidade das formas que compõem o espaço biográfico possui o traço comum de contar, ainda que de diferentes formas, experiências de vida - seja essa vida pessoal ou relacionada à atividade artística. Assim, ao compreendermos o espaço biográfico não como uma especificação particular de cada gênero e sim como o entre-lugar de interatividade entre eles, nos conectamos a uma nova tendência das narrativas contemporâneas, que privilegia a convergência de mídias como estratégia central para atrair diferentes públicos em torno de uma obra. Tendência essa que se apoia, por sua vez, em um velho costume de nossa cultura, oferecendo novos suportes para uma antiga prática, a das escritas de si. Desse modo, nos aponta Arfuch:

Contudo, não é somente o universo das correspondências que acusa o impacto da
internet, mas a totalidade do espaço biográfico, que se abre à existência virtual:
sites, páginas pessoais, diários íntimos, autobiografias, relatos cotidianos, câmaras
perpétuas que olham - e fazem olhar -, experiências on line em constante
movimento, invenções de si, jogos identitários, nada parece vedado à imaginação do
corpo e do espírito. No entanto, essa liberdade sem necessidade de legitimação e
sem censura, essa possibilidade de desdobrar ao infinito redes inusitadas de
interlocução e sociabilidade - ao mesmo tempo anônimas e personalizadas,
investidas de afetividade e descorporizadas -, não altera em grande medida o
esperável - e sem dúvida estereotípico - dos velhos gêneros. (...) A internet
conseguiu, assim, popularizar novas modalidades das (velhas) práticas
autobiográficas das pessoas comuns, que, sem necessidade de mediação jornalística
ou científica, podem agora expressar livre e publicamente os tons mutantes da
subjetividade contemporânea. (ARFUCH, 2010, p. 149-150)

Mas, se a proliferação dos discursos em primeira pessoa não destoa da tendência cultural contemporânea, que encontra nos antigos cânones autobiográficos sua base de sustentação, acrescenta, por outro lado, uma nova lógica ao mercado editorial, centrada na exploração midiática dos autores como elemento chave para a valorização dos textos escritos. Para discutir tal questão, trabalharemos, a seguir, alguns aspectos relacionados ao escritor brasileiro João Paulo Cuenca e duas de suas obras literárias: Corpo presente (2003) e O único final feliz para uma história de amor é um acidente (2010). Serão também analisadas, em conjunto com as obras citadas, as estratégias de divulgação e apresentação do autor, que desde sua primeira publicação, em 2003, marca uma forte presença na internet, através de seus mais variados suportes. 
Inspirados no mapa do território que Leonor Arfuch traça no primeiro capítulo de $O$ Espaço Biográfico - Dilemas da Subjetividade Contemporânea, apresentamos as coordenadas que nos levaram a escolher, dentre as infinitas possibilidades existentes, alguns espaços digitais de enunciação. Apoiados na ideia de que os meios interferem diretamente nos conteúdos que neles (e a partir deles) são construídos, entendemos que o acesso gratuito a esse cardápio diversificado de opções, somado à possibilidade de manifestar-se acerca de qualquer coisa, certamente influem na forma como os escritores elaboram suas formas de (se) dizer o (no) mundo. Estaríamos, pois, diante de um fluxo circular de afetações: ao mesmo tempo em que os novos suportes tecnológicos influenciam os processos de subjetivação contemporâneos, seriam também as novas formas de se pensar e fazer arte que funcionariam como orientadoras das escolhas pelos meios mais adequados de enunciação.

Walter Benjamin, em “A obra de arte na era da reprodutibilidade técnica” (2000), defende a ideia de que a arte espelha as mudanças sociais. De acordo com sua teoria, com o surgimento da sociedade de consumo, há uma alteração no valor antes proferido às obras de arte. Outrora sacralizada, a arte teria se tornado, graças ao desenvolvimento técnico que possibilitou meios para sua reprodução e divulgação, mercadoria. Como consequência das relações que se estabelecem a partir desse novo cenário, há também grandes mudanças na produção de subjetividades e, consequentemente, há, em nosso campo de trabalho, o surgimento de novas formas textuais.

Como reflexo dessa nova visão da arte, entendemos que hoje, para habitar um lugar de destaque na cena literária contemporânea, é preciso que o autor jogue com a sua própria voz, escolhendo espaços para uma infindada construção narrativa. É preciso, pois, que os textos sejam escritos para além dos livros publicados, em uma narrativa que se tece em diferentes meios e nunca se encerra, uma vez que, a todo o momento, novos elementos podem ser acrescentados à obra. Dentro desta perspectiva, trabalharemos com os espaços de e(u)nunciação utilizados por João Paulo Cuenca, escritor que, nos últimos anos, fez das plataformas digitais importantes meios para divulgação, apresentação e criação de suas obras. Dentre as infinitas possibilidades de formas não canônicas compreendidas no emprestado espaço biográfico de Arfuch que utilizamos como solo fértil para a construção de nosso trabalho, priorizaremos a análise da presença performativo-midiática de Cuenca em seus blogs, Twitter, Facebook, Formspring e YouTube.

João Paulo Cuenca é o que podemos chamar de um típico escritor contemporâneo. Tendo começado sua carreira na redação de um blog intitulado Folhetim bizarro (1999-2001), 
teve seu primeiro livro, Corpo presente, publicado pela editora Planeta, em 2003. De lá para cá, Cuenca tem se apresentado como um versátil profissional da palavra escrita: além do livro já mencionado, publicou outros três romances ( $O$ dia mastroianni, Agir, 2007, O único final feliz para uma história de amor é um acidente, Companhia das Letras, 2010, e A Última madrugada editora LeYa, 2012). Fez, também, parte de diversas antologias e atuou como roteirista em diferentes programas de televisão, como a série Afinal, o que querem as mulheres?, produzida pela Rede Globo de Televisão em 2011.

A escolha por trazer esse escritor para a cena de nosso trabalho não é aleatória. Deve-se, principalmente, ao extenso campo que nos oferece por tratar-se de um autor com forte presença na mídia (uma vez que atua também como cronista e crítico cultural em jornais) e, o que mais nos importa, na internet e em seus suportes. Baseamos nossa hipótese em uma breve análise de sua primeira experiência autoral com Corpo presente, que teve na internet sua principal fonte de divulgação, e parece ter sido o pontapé inicial para a criação de uma estratégia do autor para inserção no mercado editorial. Isso porque, apesar de já ter declarado em uma entrevista que, para ele, um escritor é aquele que escreve livros, Cuenca baseia seus trabalhos em experiências transmídias, que com frequência ampliam o espaço literário para as redes sociais e outras linguagens, como a audiovisual.

Apesar do vasto leque de opções que Cuenca oferece, centraremos nossa investigação em duas de suas experiências: a sua já mencionada primeira publicação, e sua experiência na produção de um livro sob encomenda, intitulado $O$ único final feliz para uma história de amor é um acidente, que é parte integrante do projeto Amores Expressos, da editora Companhia das Letras.

Corpo presente é um livro que traz como tema a busca da criação e da escrita como possibilidade única de salvação em vida. No livro, uma sequência de textos nomeados com números primos e narrados no presente do indicativo, apresentam ao leitor uma história de amor e horror, que também pode ser entendida como uma obsessiva busca da identidade. $\mathrm{Na}$ trama, há o narrador, Alberto, e Carmem, que são eles mesmos e muitos outros, juntos, a vagar pelas noites de Copacabana. Como fio condutor dos textos, há a fixação do narrador por Carmem, traduzida em uma busca incessante que o faz seguir em frente, construindo novas narrativas, perdendo e encontrando-a em cada bar, rua ou cenário sujo de Copacabana. A Carmem de Cuenca é mãe, prostituta, amada, travesti e até o próprio narrador do livro que, em certo capítulo, surpreende, misturando-a à sua voz. Carmem é, também, o seu espelho: 
Essa procura pelo meu reflexo dentro dos seus olhos representa o caos. Paixões corriqueiras e semanais - eu estou sempre disposto a largar tudo e me perder dentro do espelho. Eu estou sempre abrindo portas e jogando tudo pra depois, perdido entre lençóis sujos, cabelos pintados e uma infinidade de cheiros de mulher. Perdido entre uma enorme vontade de abraçar todas vocês e um enorme medo de perder tudo isso que eu quase-tenho (CUENCA, 2003, p. 88)

O que João Paulo Cuenca propõe em seu primeiro livro é um jogo de identidades, narrado em um eterno presente, de memórias misturadas em um contínuo confronto subjetivo. Confronto corporificado no tempo presente da transformação do processo de criação da obra em uma espécie de making off, disponibilizada para o público leitor em um blog atualmente fora do ar e de nome 'Carmem Carmem', lançado após ter recebido a proposta de publicação pela editora Planeta. O autor, entretanto, parece fazer questão de esclarecer a ordem dos fatos, uma vez que, em Corpo presente, afirma que seu livro não é um exemplo de um blog que vira livro, mas, ao contrário, seu blog é que tem como tema o seu livro e seus processos de criação.

Se a estratégia de Cuenca de utilizar a internet como meio para divulgação de sua produção artística e apresentação enquanto autor literário foi acertada, outro evento de importante impacto proporcionou ao livro Corpo presente um lugar de destaque na crítica e na mídia contemporâneas. Em um vídeo disponível no canal da livraria Saraiva no YouTube, o autor conta que, no mesmo ano em que lançava seu primeiro romance, foi convidado a participar de uma experiência literária, na qual deveria, ao passar alguns dias em Parati, escrever um conto que tivesse a cidade histórica como cenário. O livro (Parati para mim) foi lançado na primeira edição da FLIP - Festa Literária Internacional de Parati -, e Cuenca, por ocasião do lançamento da coletânea de contos, participou da primeira mesa de escritores da Festa. Fato esse que, segundo o escritor, impactou diretamente na recepção de Corpo presente no mercado cultural:

\footnotetext{
A FLIP não tinha essa dimensão. Eu fiquei 25 dias em Parati, fora de temporada pra escrever um conto baseado na experiência de tá em Parati. Um conto que se passasse em Parati que saiu nesse livro Parati Para Mim que saiu na primeira FLIP. E a mesa foi a primeira mesa da história da FLIP e é uma sensação engraçada porque com 24 anos ali eu vi a FLIP estourar. Por causa da FLIP o meu livro [Corpo Presente] teve muito mais atenção, não se imaginava a dimensão midiática que ela ia ter... De capa dos principais cadernos de cultura... Desde isso até flashes ao vivo no Jornal Nacional. (CUENCA, 2009)
}

Outra importante experiência literário-midiática do autor é o mais recente livro $O$ único final feliz para uma história de amor é um acidente, da coleção Amores Expressos. $\mathrm{O}$ projeto, concebido pelo produtor Rodrigo Teixeira, enviou dezessete autores brasileiros para passarem um mês em diferentes cidades do mundo, com a tarefa de, a partir das experiências 
vivenciadas, criarem histórias de amor ambientadas nos cenários visitados. Desta forma, dezessete autores brasileiros de diferentes gerações foram convidados a integrar este projeto e viajaram pelo mundo para observar diferentes possibilidades amorosas na contemporaneidade. Com grande parte dos livros já publicados, o projeto apostou na experiência do deslocamento como combustível para a concretização da proposta inicial da coleção, que, como resultado final, se propõe a criar um quebra cabeças literário, montado através de diferentes pontos de vista sobre o fenômeno amoroso no mundo de hoje.

Típico exemplo de uma experiência midiática de convergência de mídias, o projeto, que contou com a participação do João Paulo Cuenca também como coordenador editorial, previu, desde o início, a transposição dos romances para as telas cinematográficas, além da realização de um documentário sobre a estada dos escritores nas cidades para onde foram enviados para escrever os romances e da criação de blogs pessoais, nos quais todos os escritores participantes registraram, cotidianamente, com textos, vídeos e fotos, as experiências vividas a partir da participação no projeto.

Em seu blog <http://blogdocuenca.blogspot.com.br>, Cuenca narra com detalhes aspectos de sua experiência no lugar que lhe foi destinado, Tóquio/ Japão. Em uma narrativa que se assemelha aos tradicionais diários de viagem, o escritor conta suas vivências como estrangeiro em uma terra que, devido às grandes diferenças culturais entre Ocidente e Oriente, se apresenta como um cardápio de infinitas novidades. Ao narrar as sensações sentidas nos primeiros dias de sua viagem, o autor escreve:

Como disse antes, é como se estivesse sob o efeito de uma droga muito forte. Ando com as mandíbulas trincadas, como se tivesse me entupido de anfetamina.(...) Consulto um mapa às duas da manhã e resolvo que tentarei voltar andando de Shibuya até o hotel, que fica pra lá de Ginza, mas só consigo ir até Roppongi, numa caminhada impressionante sob interseções de viadutos gigantescos, uns sobre os outros. São três da manhã e ando sob pontes e túneis. Num pontilhão sobre um viaduto, de onde tenho vista panorâmica de um engarrafamento, sento no chão e escrevo algo que não entrará neste diário. (CUENCA, 2007)

Há na experiência narrativa de Cuenca em seu blog uma espécie de jogo representativo. Da mesma forma que o autor parece se esforçar para contar em detalhes o que encontra na cidade desconhecida, ao incluir em seus posts fotos e vídeos que permitem ao leitor mergulhar junto ao escritor na experiência, há anúncios de conteúdos não ditos. É também notável uma clara seleção pelos temas escolhidos. Seguindo o mesmo estilo que o autor apresenta na composição de Corpo presente, o blog de registros de Cuenca no projeto Amores Expressos versa sobre a Tóquio de seus olhos, atentos para o material que coleta, imageticamente, para a composição de seu romance. Estaria, pois, na claustrofobia incessante 
da cidade, representada pela repetição de posts sobre sexo, drogas e espaço paranóicos, a matéria fértil para a posterior redação de seu livro. Assim o autor nos oferece como pista:

\begin{abstract}
Dentro de uma das várias lojas especializadas em pornografia, tentei procurar com a ajuda do Mucha revistas sobre "dutch wifes" ou "love dolls", que são basicamente bonecas infláveis muito sofisticadas e hiper-realistas. Aqui, são feitas de silicone, chegam a custar cerca de seis mil dólares e são inteiramente customizáveis (e você deve ter entendido o "inteiramente"). Quando seu dono morre ou resolve descartá-la, as lojas realizam funerais budistas com as bonecas. (...) Talvez eu resolva escrever algo sobre elas. (CUENCA, 2007)
\end{abstract}

Em seu romance, lemos, de fato, as experiências de uma boneca. Além dela, há, no intenso ritmo de Tóquio, um submarino que percorre os espaços subterrâneos da cidade em busca de imagens de um jovem executivo. O executivo é Shunsuke, um jovem japonês apaixonado por uma garçonete polonesa-romena (Iulana), espionado por seu pai, o grande poeta japonês, Sr. Okuda. Conquistador inveterado, Shunsuke, acostumado a criar uma identidade para cada namorada que conhece nos bares do distrito de Kabukicho, tem sua rotina abalada pelo aparecimento de Iulana. A garçonete é, entretanto, apaixonada por uma dançarina com quem divide um apartamento e não se comunica bem em japonês, mas nada disso impede que os dois iniciem uma relação conturbada. O maior problema, contudo, é o fato de os dois estarem sendo constantemente espiados pelo pai de Shunsuke. Durante toda a trama, Sr. Okuda aparece como um vilão sempre presente e obstinado em acabar com qualquer possibilidade de felicidade do filho, ao mesmo tempo em que tece uma história de amor com Yoshiko, uma boneca erótica cativante, de personalidade ingênua e filosófica.

A história é narrada em um futuro próximo por Shunsuke e Yoshiko, cuja narração de boneca recebe destaque de cor e forma em um vermelho itálico que compõe a estética do romance. Em toda a trama, o autor se apropria da cultura japonesa de ontem e de hoje, para contar uma história de amor nada convencional, em que a vida fragmentada das grandes cidades, o voyeurismo e a obsessão estão em toda parte. Voyeurismo esse que se expande para além do livro, uma vez que o leitor é, a todo o momento, convidado a espiar, no projeto Amores Expressos, o processo de criação das obras que lê.

Como quem brinca com o prazer que provoca no leitor espião, Cuenca tece uma narrativa bastante visual, explorando textualmente cores e cheiros, através de uma minuciosa descrição das cenas que conta. Estratégia voyeur que o autor parece dominar com facilidade, ao se apropriar da conectada sociedade contemporânea, para expor em mídias sociais, e em um número surpreendente de entrevistas, diversos elementos que constituem sua narrativa. Dessa forma, ao nos debruçarmos sobre esse material, vemos que o fetiche exibicionista da 
nossa sociedade é, a todo o momento, trabalhado por Cuenca como mais uma camada narrativa, na qual o leitor não apenas acompanha a vida do protagonista Shunsuke, como também espia a vida do escritor João Paulo Cuenca, que tece essa interminável narrativa, acrescida de diferentes elementos jogados em cada nova pista deixada na rede pelo autor.

Assim podemos observar a partir dos diálogos tecidos pelo escritor com o seu público, por meio de sua conta pessoal no Twitter. Através dela, Cuenca compartilha com seus leitores o processo de finalização e lançamento da obra, conforme nos mostram as seguintes postagens realizadas na ferramenta:

João Paulo Cuenca@jpcuenca: partiu RT @cialetras Hoje, a partir das 19h, @jpcuenca estará na @LivTravessa de Ipanema para o lançamento de !O único final feliz..." (CUENCA, 2010)

João Paulo Cuenca @jpcuenca: ACABOU - os originais de "O único final feliz para uma história de amor é um acidente" foram pra gráfica. (CUENCA, 2010)

Dentro da mesma perspectiva de utilização das novas mídias como ferramentas para o seu trabalho, João Paulo Cuenca, em dezembro de 2009, ofereceu um prato cheio aos seus leitores. Antenado em relação às novas tecnologias e por ocasião do grande sucesso que a recém lançada ferramenta virtual Formspring fazia no Brasil, o escritor resolveu utilizá-la para realizar uma experiência literária. Assim, no dia 16 de dezembro, publicou no blog que mantém no site do jornal O Globo:

Durante sete dias (15-22 dez 2009) responderei TODAS as perguntas anónimas que me forem feitas no formspring (não responderei perguntas que envolvam terceiros). Antes de escrever, saiba que está sendo usado. Isso aqui é um experimento ficcional. Dele somos cobaias. (CUENCA, 2009)

Como resultado da experiência que utilizamos como símbolo síntese da hipótese que defendemos no presente trabalho, Cuenca recebeu, em média, 400 perguntas anônimas por dia. Tendo respondido todas, o autor, ao final da semana, afirmou não saber ainda o destino que iria dar ao material produzido. Irônico e contraditório como costuma se apresentar, apontou a possibilidade de utilizá-las na construção de uma narrativa baseada em perguntas, na montagem de uma instalação ou, ainda, de imprimi-las em folhas de papel para queimá-las em uma fogueira. Em explicação posterior à semana de perguntas, Cuenca compartilhou com o público sua motivação, que é também nossa, e o fez investir na experiência:

Há tempos me interessa investigar a relação passional e cada vez mais íntima que existe entre um "artista" (muitas aspas) e quem o consome. Especialmente entre um escritor de 31 anos, com pequeno apelo midiático, e seu restrito, mas extremamente conectado e interativo, público. (...) Por isso, na última terça, inaugurei um 
formspring. Que é nada além de um site na internet onde qualquer um pode, anonimamente, me enviar uma pergunta. (CUENCA, 2009)

É, portanto, a partir das pistas que Cuenca deixa em diferentes espaços de enunciação, que podemos ler - transversalmente - as suas obras. Parece-nos, por fim, que, em um momento no qual cada vez mais celebridades instantâneas surgem e desaparecem, é na consciente estratégia de diálogo com o seu público que o autor encontra espaço para se manter por quase uma década em um lugar de destaque no disputado circuito artísticoliterário da atualidade.

\section{Finalizações não conclusivas}

Neste trabalho que agora encerramos, buscamos traçar um breve panorama de um fenômeno cultural de nosso tempo, relacionado ao conceito de autoria como performance, a partir do entendimento de que o escritor da atualidade representa diferentes papeis para se fazer percebido, falando de si e inscrevendo suas experiências em diferentes cenários.

$\mathrm{O}$ advento das novas tecnologias e a grande proliferação das escritas de si em blogs e redes sociais são, em nosso ponto de vista, sintomas de época que dialogam com o campo dos estudos literários e apontam para um novo objeto de pesquisa. O fenômeno que estudamos, implica, também, em uma nova lógica da produção textual de nosso tempo. Entendendo, a partir de Hebert Marshall McLuhan (1974), que o meio é a mensagem, buscamos nos debruçar sobre os novos cenários da escrita para analisar de que forma os espaços digitais de enunciação dialogam com as obras e produções artísticas contemporâneas.

Para tanto, iniciamos o presente trabalho com uma localização histórica do conceito de autoria. Preocupados em datar nossa análise, nos apoiamos na ideia de que a noção de autor foi construída, desconstruída e reconstruída de acordo com os diferentes momentos de nossa história. Entendemos, a partir disso, o retorno do autor e sua crescente exploração midiática como um fenômeno cultural de nosso tempo e passível, portanto, de mudanças futuras.

Ao refletir sobre os novos meios de enunciação, utilizados por escritores para apresentação, criação e divulgação de suas obras, nos apoiamos no conceito de espaço biográfico desenvolvido por Leonor Arfuch, que nos permitiu um olhar transversal sobre os diferentes lugares nos quais João Paulo Cuenca joga com a sua própria voz, através de uma escolha consciente por espaços para uma infindada construção narrativa.

Debruçamo-nos, por fim, na análise de alguns aspectos relacionados ao escritor e duas de suas obras literárias e às estratégias de divulgação e apresentação do autor, que, desde 
sua primeira publicação, em 2003, marca uma forte presença na internet, através de seus mais variados suportes.

Nesse sentido, observamos, por fim, a grande importância que a constante apresentação do autor em diferentes meios tem para o reconhecimento e sucesso do seu trabalho. Foi possível, também, encontrar, em suas publicações, um constante diálogo com o seu tempo, expresso tanto a partir das temáticas escolhidas, quanto do estilo narrativo do autor, predominantemente conciso e imagético.

\section{Referências}

AGAMBEN, Giorgio. Genius. O autor como gesto. In: Profanações. Trad: Selvino J. Assmann. São Paulo: Boitempo, 2007.

ARFUCH, Leonor. O espaço biográfico: dilemas da subjetividade contemporânea. Rio de Janeiro: EDUERJ, 2010.

BARTHES, Roland. Deliberação. In: O rumor da língua. São Paulo: Brasiliense, 1988.

BENJAMIN, Walter. A obra de arte na época de sua reprodutibilidade técnica. In: ADORNO et al. Teoria da Cultura de massa. Trad. de Carlos Nelson Coutinho. São Paulo: Paz e Terra, 2000. p. 221-254

BLANCHOT, Maurice. A solidão essencial. In: O espaço literário. Trad. Álvaro Cabral. Rio de Janeiro: Rocco, 1987

CUENCA, João Paulo. Corpo presente. São Paulo: Planeta do Brasil, 2003.

O único final feliz para uma história de amor é um acidente. São Paulo: Companhia das Letras, 2010.

FOUCAULT, Michel. O que é um autor? 6.ed. Lisboa: Passagens, 2006.

KLINGER, Diana Irene. Escritas de si, escrita do outro: o retorno do autor e a virada etnográfica. Rio de Janeiro: 7Letras, 2007.

LEJEUNE, Philippe. O pacto autobiográfico: De Rousseau à Internet. Belo Horizonte: Editora UFMG, 2008.

McLUHAN, Herbert Marshall. Os meios de comunicação como extensão do homem. São Paulo: Editora Cultrix, 1974.

VIEGAS, A. C. C. O retorno do autor - relatos de e sobre escritores contemporâneos. In: VALLADARES, Henriqueta Do Coutto Prado (org.). Paisagens ficcionais: perspectivas entre o eu e o outro. Rio de Janeiro: 7Letras, 2007.

. A ficção brasileira contemporânea e as redes hipertextuais. In: Revista Brasileira de Literatura Comparada Rio de Janeiro, v. 9, p. 213-227, 2006. 
Blogs e redes sociais - acessados em julho de 2012

https://twitter.com/\#!/jpcuenca

http://www.facebook.com/jpcuenca

http://www.formspring.me/jpcuenca

http://blogdocuenca.blogspot.com.br/

http://oglobo.globo.com/blogs/cuenca/

http://www.youtube.com/watch?v=F4kzq5yyaQ4

http://www.youtube.com/watch?v=FMb89-Vd660\&feature=related

[Recebido em agosto de 2012 e aceito para publicação em outubro de 2013]

\section{Writing, performance and self-representation}

Abstract: Assuming that the advent of new technologies and the vast proliferation of self narrative on blogs and social networks are symptoms of this time that dialogue with the field of literary studies and appoint to a new object of research, this paper aims to draw a brief overview of a cultural phenomenon of our time, related to the concept of authorship as performance. Based on the understanding that the contemporary writer performs different roles to be noticed, talking about themselves and their experiences in different scenarios, we will work with the spaces of enunciation used by João Paulo Cuenca that, in recent years, has used digital platforms as important means of dissemination, presentation and creation of his works.

Keywords: Self narrative. Performance. Authorship. João Paulo Cuenca.

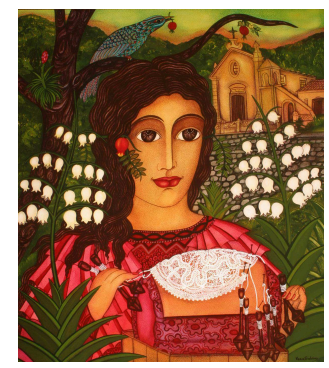

